\title{
Application of modern technologies in the management of records in public libraries
}

\author{
Tlou Maggie Masenya \\ Durban University of Technology \\ tm.masenya@webmail.co.za
}

Received: 08 May 2020

Revised: 09 July 2020

Accepted: 29 August 2020

\begin{abstract}
Many organisations, including libraries and information centres are struggling to manage their records. Effective management of records ensures the public library's ability to function effectively and provides documentary evidence of scholars and citizens. Recently, modern technologies such as blockchain, cloud computing and Internet of Things (IoT) have increasingly been adopted by various organisations to manage records while other organisations are slow to adopt them. Public libraries are positioning themselves to take this advantage by implementing innovative technologies to manage their records. This study utilised literature review to investigate the application of modern technologies in managing records in public libraries with the view to highlight how these technologies can revolutionise library practices. The study established that although public libraries acknowledge the importance of modern technologies such as blockchain, cloud computing and Internet of Things in managing their records, these technologies are being slowly adopted due to lack of information technology infrastructure, technical support, and knowledge and skills. Therefore, all these challenges made it difficult for librarians and information professionals to maximise the benefits of these technologies and they struggle to see how these technologies can be incorporated into their institutions. Public libraries thus need to better understand best practices for records management, which may go a long way in influencing library policy to support records-management processes. The study recommends that public libraries consider exploring collaborating with other sectors such as archival services to implement modern technologies for the purpose of managing records.
\end{abstract}

Keywords: modern technologies, library records, public library, blockchain, cloud computing, Internet of Things

\section{Introduction}

Durst and Wilhelm (2012) acknowledge that libraries played a major role in South Africa's national life and liberation struggles through cultural and political influences. As noted by Iwhiwhu and Okorodudu (2012), public libraries are established, supported and funded by the community, either through local, regional or national government or through some other form of community organisation. According to Yakel and Colligan (2001), public libraries have long been used to document and support the writing of library history and are expected to deliver high quality information to their patrons in a reasonable time. The library records are an integral form of evidence concerning the accountability to the citizens, including such diverse categories of records as administrative records, registration files, financial records and historical records. Public libraries are under increasing pressure to become more effective in 
managing their records and therefore they need to adhere to the best practices and develop innovative technologies to ensure their continued value as evidence. As the public libraries are sustained through public funds, the records generated by these entities have to be managed according to archival legislation.

Effective management of records thus ensures the public library's ability to function effectively and provides evidence of accountability. However, Niederberger (1999) reported separate incidents in the Pittsburgh Post-Gazette highlighting poor record-keeping in public libraries resulting in poor accountability and loss of massive digital memory and cultural heritage. This led to the examination of the management of public library records, access to their records and librarians' awareness of the legislation concerning recordkeeping. Public libraries may meet users' information needs by acquiring, organising, managing and making relevant information resources delivered through modern technologies (Iwhiwhu \& Okorodudu 2012). It is therefore necessary for any public library to embrace the use of modern technologies in order to perform well and meet the needs of the users in these trying times. During the State of the Nation Address in 2018, President Cyril Ramaphosa reiterated that the prosperity of South Africa as a nation depends on its people's ability to take full advantage of rapid technological change. This means that, as a country, South Africa urgently need to develop capabilities in the areas of science, technology and innovation. The president emphasised that government will soon establish a digital industrial revolution commission to ensure that our country is in a position to seize the opportunities and manage the challenges of rapid advances in digital technologies. These innovative technologies can also bring about changes in business transactions and the production, administration, management, preservation and access of records.

Public and academic libraries over the world are increasingly deploying modern technologies in their activities and operations, and they have come to rely on a growing array of these technologies to create, store and manage their records. However, with more libraries managing their collections, policy concerns and procedures are also becoming increasingly important. In order for records to be used in their evidentiary capacity, they must be created, managed and preserved, respecting applicable policies, legislation, regulations, standards, codes of practice, procedures and community expectations (Shepherd \&Yeo 2003). Implementation of policies, procedures and appropriate strategies are thus vital for effective management of records and should be documented so that they may be sustained and understood over time. International standards such as ISO 15489 also established the core concepts and principles for the creation, capture and management of records. Records management systems should therefore comply with organisational legal requirements to ensure that records are always trustworthy, accessible, legally admissible and durable (ISO 15489-1 2016).

As noted by Raju (2014), the explosive growth of digital devices and related applications have collectively altered the traditional library beyond recognition. These dramatic changes to modern digital environment have prompted several projects and initiatives such as developing digital libraries and institutional repositories. Digital libraries appeared as a new mechanism for managing scholarly production, dissemination and preservation of records in both public and academic libraries. As pointed out by Ross (2007), if we think more carefully about digital libraries, we easily observe that they may be libraries by name, but they are archives by nature and the content they hold does not really need to be held elsewhere because net- based services mean it can be provided from a single source wherever and whenever it is wanted. IFLA/UNESCO (2010) described digital library as an environment that brings together collections, services and people in support of the full life cycle of creation, management, 
preservation and dissemination of digital information, and applying new technologies to provide access to digital collections. In 2005, the United Nations Educational, Scientific and Cultural Organisation (UNESCO) and the Coalition of South African Consortia (COSALC) held a workshop at the University of Cape Town (UCT), known as Building Digital Library Collections using the greenstone, attended by delegates from Ethiopia, Lesotho, Namibia, New Zealand, Swaziland, Sudan and South Africa. The workshop was aimed at:

- Raising awareness of open access models for information exchange.

- Building capacity of information and communication technologies (ICT) professionals in African institutions.

- Providing archivists and librarians in Africa with the skills to utilise electronic information tools and resources in their work and enhancing access to online resources (UNESCO, 2005).

In practice, the majority of African libraries, particularly in South Africa, have already established digital libraries, and only a few are at some intermediate stage. However, as observed by the Council of Canadian Academies (2015) libraries, archives and museums are facing numerous challenges in their attempts to adapt to the digital age. These include dealing with rapid obsolescence of the technology used, making accessible mass quantities of digital data and remaining trusted as repositories that hold documentary evidence of scholars and citizens. Public libraries thus need to strategise and propose technologies that could ensure that their records in different electronic formats and media such as text, videos, audio, graphics, emails and digital images are available and accessible at all the times. Modern technologies such as blockchain, cloud computing and IoT can be some of the ways to deal with the challenges of managing records within public libraries as they will ensure that library records can be stored, managed properly and accessible anywhere.

\section{Problem statement}

Records management is part of the daily operational activities in public libraries that are often overlooked. Vital records have been destroyed while others are difficult to access due to poor records management and are not identified as important evidence for sustaining the institutions. File cabinet storage proved to be inefficient use of space and this may explain why libraries have not been able to save more records. Therefore, public servants and information professionals have to maintain accountability to the citizens they serve. However, effective management of library records became a vital challenge over the past years. Public libraries in South Africa and around the world have adopted modern technologies such as blockchain, cloud computing and IoT technologies to mitigate these challenges. Gartner (2016) proclaims that application of these modern technologies in managing records can fundamentally change the society we live in. Although public libraries have shown great interest in the implementation of modern technologies, technological innovation has always been a key challenge in storing and managing records. A move from file cabinet storage systems towards the digital management systems was never painless. Proper management of library records continues to be a challenge due to a lack sufficient skills, policy, procedures and standards, as well as a lack of knowledge of how to utilise modern technologies in managing library records. This underscored the need for greater technical expertise to manage records and develop policies to support records management practices. Although modern technologies offer a viable trusted alternative to record keeping, the level of adoption of these technologies is low in public libraries in South Africa. It also appears that little academic research has been conducted on 
the application of modern technologies with practically nothing conducted on the management of library records (Lemieux 2016). This study thus attempts to fill the gap that exists between traditional and modern methods of managing library records. The following objectives were formulated to address this research problem:

- To establish the extent to which modern technologies have been adopted in public libraries in managing records.

- To determine the factors enabling and hindering the adoption of modern technologies in public libraries.

- To determine the capacity of the human resources to utilize modern technology in managing records.

\section{Research methodology}

This study explores literature to critically analyse the application of modern technologies in the management of records in public libraries in South Africa. A similar study by Modiba, Ngoepe and Ngulube (2019) investigated the application of disruptive technologies to the management and preservation of records in the public sector in South Africa and was also based on critical analysis of literature review. To carry out the literature review, the author searched the relevant articles on previous studies and initiatives reporting on the application of modern technologies to the management of records and their challenges. Therefore, data was collected from secondary sources, including books, journals and research reports published by governmental and international agencies available on official websites. Additional searches of relevant grey literature, including unpublished research commissioned by governments, private or public institutions and policy briefs from public sector institutions, were identified through electronic searches. This methodology was used to apply and increase knowledge in a particular area of research, thereby showing proficiency in reviewing, synthesising and critically analysing the relevant research literature.

\section{Findings from literature review}

The findings are discussed in line with the study objectives.

\subsection{Adoption of modern technologies for the management of digital records}

Library records continue to increase in multiple formats and if they are not properly managed, there can be a delay or no access to these records. Therefore, the more efficient the management of library records, the more effective access is provided. However, today, libraries and other information centres are faced with the challenge of organising and managing their hybrid resources which include print and electronic resources (Nwosu 2017). The development of modern technologies is therefore imperative to pinpoint issues pertaining strategies for management of library records in the public library environment. The proper management of records thus calls for organisations to adopt modern technologies such as blockchain, cloud computing and IoT.

\subsubsection{Blockchain technology}


Blockchain is an innovative technology that has the capacity to transform the delivery of private and public services through new applications. Deloitte (2016) describes a blockchain as a distributed ledger of all transactions, which are recorded in discrete blocks and linked together in a chain, and each block contains private data and a public header that is used to link to the next block on the chain. Blockchain comprises data records or blocks, and once these blocks are collected in a chain, they cannot be changed or deleted by a single actor; instead they are verified and managed using automation and shared governance protocols (Blockgeeks 2016). The blocks are sequentially linked and cryptographically secured in such a way that only the owner of data in a block can unlock it using their private key (Straw 2016). Shaw (2016) further describes blockchain technology as a shared electronic database in which the data records are immutable and encrypted, and these data records can be shared within a group of people, organisations or a community. The shared document is encrypted and verified to ensure that the data it stores is always correct and every record added to the blockchain ledger has a unique key associated with it that can be trusted (Shaw 2016). Therefore, the use of unique key encryption is important because it enables the owner of the information to control it without giving up personal information like names or social security numbers (Shaw 2016). Tapscott and Tapscott (2016) further describes blockchain as 'incorruptible', programmable to record not just financial transactions, but virtually everything of value. There are three main attributes of blockchain, namely: decentralisation, trust and immutability.

- Decentralisation blockchain means that the network operates on a peer-to-peer basis and works by linking all participants in a marketplace without intermediaries in such a way that each transaction is transparent to all the participants in the network (Blockgeeks 2016).

- Trust blockchain has emerged as a new type of trust for global services, particularly financial services, and it relies on existing technology to solve an old problem; for example, how do two parties conduct a transaction without knowing or trusting each other and without a trusted third party intermediary (Trautman 2016).

- Immutability means that once data or transactions are appended, accepted and confirmed by the nodes on the blockchain, it is not easy to change it. It is therefore an append-only data store and no deletes or edits are allowed, hence this technology has its capability as an unimpeachable record keeper (Umeh 2016).

Blockchain is thus regarded as essentially database that is being maintained centrally and duplicated across a network in such a way that every change to each database is recorded and approved on each node on the network (Bauerle 2017). It has the following unique advantages as summarised by Bauerle (2017):

- Anonymity: parties who come to a blockchain can engage in trusted exchanges without revealing their identities, which cuts down on time.

- Distributed structure: any two or more people can create a blockchain without going through the process of registering with a central authority and they can even create a private blockchain that have different custom security definitions that limit what participants in the chain can do.

- Cost savings: this is the most obvious benefit because blockchain transactions do not require intermediaries. Therefore, processes can be made more efficient and less expensive and there is no need for auditors or legal professionals to validate the authenticity of information.

- Efficiency: fewer people means faster turnaround and, therefore, transactions that might take days waiting for multiple sign-offs can be concluded in seconds. 
- Security: the fewer participants there are in a transaction, the lower the risk that something could go wrong. Handoff points are a prime vulnerability and blockchain effectively eliminates them.

- Flexibility: any digital asset can use blockchain, including difficult-to-protect items like multimedia and email records.

- Competitive advantage: companies in the intellectual property space such as law firms and stock photo agencies can also consider using blockchain to offer new services that benefit both buyers and content creators.

With regard to records management, blockchain technology has the potential to impact all records management processes and extend their capabilities, and it also has broad implications for securing and authenticating intellectual property at a lower cost and higher efficiency (Gartner 2016). The inherent characteristics of blockchain architecture and design provide properties like transparency, robustness, auditability and security (Christidis \& Devetsikiotis 2016). Blockchain technology also enables people who do not know each other to engage in trusted transactions with full confidence in the integrity of the assets being exchanged. It does this by embedding authentication into the document itself and using a closed loop tracking system to protect against tampering or modification. Blockchain can thus help to trace people who accessed digital records and ensure that digital records in integrated systems are accurate and secure. In this regard, a digital record can be accessed anywhere in the country, leaving a digital trail for a system that can be trusted inherently. Public libraries can therefore consider using blockchain technology, especially for security of their digital records because with this technology, it is impossible to change information without leaving a digital trail (Lemieux 2016). Blockchain technology creates a digital trail to verify the current state of the digital information including all changes that have been made along the way. Digital trail makes it possible to see exactly when the data was changed, by whom and the method that was used. Public libraries can use this audit trail to trace any changes made or if their digital records have been tampered or altered in an unauthorized manner.

On the other hand, blockchain can also help public libraries in digitising existing records and manage them within a secure infrastructure. Once digital information is committed onto a blockchain, it is permanently stored and impossible to manipulate or hack. This technology has a tracking system to ensure the integrity of data at all times. As such, public libraries can operate more efficiently with greater trust in information security. IT departments in public libraries may also be able to create rules and algorithms that allow data in a blockchain to be automatically shared with third parties once predefined conditions are met (White Paper 2019). However, as noted by Rein and Peterson (2015), despite libraries' best efforts to protect their systems, criminals might gain access to their databases and steal or manipulate records. For instance, in 2015, hackers obtained personal details, social security numbers, fingerprints, employment history, and financial information for about 20 million individuals who had been subject to a background check by the US government (Rein \& Peterson 2015). Although encryption methods may not be 100 per cent safe, blockchain technology can make similar breaches a great deal more difficult to achieve.

\subsubsection{Cloud computing technology}


Cloud computing is another emerging technology that can be used to manage library records and it consists of on-demand computing services delivered over the internet from a remote location or via an organisation's servers (InterPARES 2016). The National Institute of Standards and Technology (NIST) (2011) defines cloud computing as a model for enabling ubiquitous, convenient, on-demand network access to a shared pool of configurable computing resources (e.g. networks, servers, storage, applications and services) that can be rapidly provisioned and released with minimal management effort or service provider interaction. This technology is rapidly being adopted by public and private organisations due to its perceived potential benefits, including cost efficiency, scalability, convenience and performance (InterPARES 2016). Cloud computing has the potential to reduce costs while increasing value by allowing the more efficient use of IT resources, and fewer staff, hardware and software resources are required to support the enterprise. As also noted by Liu and Cai (2013), shifting library core applications to cloud-based services will reduce or eliminate most of or all the local technical needs in managing server hardware and operating systems that underlie the applications.

Yuvaraj (2013) observes that some libraries have increasingly stepping into the realm of digital librarianship and platforms that extend IT-obtainable capabilities, and this at length depends on using the cloud facilities. Cloud computing has therefore been regarded as a powerful tool that offers great scalability and flexibility, making it possible for librarians and users to access file storage, databases and other library applications anywhere at any time. JISC (2011) also points out that cloud-based services are set to transform the way libraries work, unleashing librarians from the administrative burden to focus on services for users and researchers. Cloud computing technology, therefore, can offer libraries and archives greater efficiency, which could lead to reduced costs and could be better for the environment, increased uptime, flexibility and scalability (Corrado \& Moulaison 2015). Some of the benefits of cloud computing include increased flexibility to quickly meet increased demands, disaster recovery, decreased software application and server maintenance, decreased capital expenses and increased security, and it is more environmentally friendly (Salesforce 2015). Therefore, public libraries can apply cloud computing to data integrity, upgrade and maintenance, intellectual property management, backups and disaster recovery. Cloud computing also has the ability to shift the risk from the enterprise to the cloud computing solution and this means that with both private and public cloud providers, the institution can shift the capital risks to the provider who is in a much better position to manage those risks. Yang and Tate (2012) asserts that the cloudbased integrated library systems allow many libraries to share useful data, for instance, sharing of full-text journal titles from electronic databases. Cloud computing technology is therefore enabling librarians to shift from the paradigm of ownership and maintenance of resources towards the provision of access to information maintained and controlled by others (Scale 2010).

\subsubsection{Internet of Things technology}

Another emerging technology for managing records is the Internet of Things, a dynamic and global network infrastructure, in which "Things" are expected to communicate among themselves and interact with the environment by exchanging data generated by sensing, while reacting to events and triggering actions to control the physical world (Liu, 2017). Badimo (2017) describes IoT as the general idea of physical objects that are seamlessly integrated into the information network, that are readable, recognisable, locatable, addressable and controllable via the internet. According to Badimo (2017), the IoT is at the core of digital 
transformation with 73 per cent of executives either researching or currently deploying this technology. Abu-Elkheir et al (2013) identify a number of design primitives that determine the logical and physical structure of data management solutions for IoT, that are organised into three main dimensions, namely data collection, data management system design and processing. Data collection elements target the discovery and identification of things and subsystems. Data management system design elements address how data is to be stored and archived while processing elements deal with the actual access to data stores.

Public libraries can effectively eliminate document and data silos between departments and take advantage of opportunities for improved productivity across the board by using IoT. This technology can assign heightened security levels to the documents with the ability to recognise confidential documents and prevent unauthorised access to digital records. IoT devices can help public libraries with document location and maintain security access levels. Several studies on the adoption and benefits of using IoT within public and academic libraries have, however, been reported worldwide. For example, Fleisch (2010) identifies the value drivers of IoT application to businesses and proposes that this technology could provide management systems with low-cost data about the real world. Pujar and Satyanarayana (2015) investigated the benefits of IoT for libraries and proposed innovative approaches such as a virtual library card, smart digital shelve, cloud services, and integrating of RFID tags or member cards to access the library and its resources. Wojick (2016) also explored the potential impact of IoT on library services and proposed a theoretical model of IoT application in library service that librarians can use to improve library services through sharing information, tracking and tracing services and pushing notification services.

Oyelude (2016) introduced an innovative application of IoT in Oracle Digital, delivering valueadded service through the cloud platform for library use. Massis (2016) explored the potential impact of IoT on the library from the security and privacy points of view and proposed the Security of Things and security management approaches. Ibrahim and Kamalrudin (2018) analysed the security requirement for IoT application in libraries and proposed a method to identify the security concern with IoT application. Renold and Rani (2013) designed a system with RFID technology for the use of library management such as stock management, tracing misplaced and mis-shelved books, and promoting easy access to library materials. Liu (2017) analysed the integration of library information resources in a digital way and proposed library data resource object model and the process of library personalised information service management.

\section{Factors enabling the adoption of modern technologies in public libraries}

Ensuring the succesful adoption of new technology can be challenging and it is therefore appropriate to review and discuss various enabling factors in public libraries. Several studies identified factors for the successful adoption of modern technologies such as blockchain, cloud computing and IoT, within public libraries including implementation of policies, proper technological infrastructure, IT knowledge and skills, proper allocation of resources and establishing collaboration and partnerships (Corrado \& Moulaison 2014; Raju 2014; Council of Canadian Academies 2015; Amron et al. 2019). A compliant records management system is imperative for all organizations to manage their records throughout their life-cycle. Policies, 
procedures and legislative frameworks set the standard for a compliant records management system, and they should be implemented within public libraries, and be communicated clearly and applied consistently throughout the process. The dramatic changes, largely the result of rapidly evolving digital technologies have impacted significantly on the knowledge and skills requirements for information professionals practicing on e-environment (Raju 2014). Information professionals must have knowledge and skills to effectively operate in eenvironment and the ability to use modern technologies for the management of digital records. Public libraries management needs to actively encourage and value continuous learning to invest heavily in staff development in order to support technological developments. An increasing number of IT specialists are also required to implement, customize and maintain sophisticated library technologies and infrastructure. This also requires innovative and creative thinking.

Institutional commitment and support have an impact on the succesful implementation of new technologies. Management has the power to adopt or reject new technologies from being used by the organization (Amron et al. 2019). One of the most important components of institutional commitment to any project is financial support. Technology implementation project may require ongoing budget commitments for technological infrastructure (equipment purchases, maintenance, network connectivity, etc.), staffing (hiring and specialised training) and outsourcing (technology implementation project be undertaken by outside vendors). Public libraries management should therefore ensure that enough financial resources are available to sustain the project.

As observed by Corrado and Moulaison (2014), libraries, archives and museums use collaboration strategies to assemble groups with necessary expertise in addressing the challenges posed by the digital environment. The Council of Canadian Academies (2015) also highlighted the external opportunities for realizing the digital age as collaborative opportunities and participatory opportunities. Collaboration and partnership with other institutions would allow public libraries to unite across international borders and work towards common goals, and they would be exposed to new ideas, strategies and be able to acquire knowledge and skills needed to exploit these innovative technologies. These memory institutions are also seeking new ways to retain their relevance by encouraging a participatory culture and contributions from the public range from sharing of historical knowledge to design of software by expert volunteers (Council of Canadian Academies 2015). Expert volunteers may help to engineer software programmes or technologies that may enable public libraries to offer unique services to their users.

\subsection{Factors hindering the adoption of modern technologies in public libraries}

Although the management of digital records has existed for such a long time, it is still challenging to adopt technologies such as blockchain, cloud computing and IoT within public libraries. The problems relating to poor IT infrastructure, lack of IT knowledge and skills, lack of technical support and lack of IT training make it difficult for public libraries to maximise the full benefits offered by these technologies. There is also a distinct lack of understanding of modern technologies and as a result, librarians and archivists struggle to see how they can be incorporated into their institutions or organisations. The potential risks of adopting these innovative technologies must therefore be fully understood by organisations in order to make 
informed decisions about its utilisation. However, it is still every library's or any other organisation's desire to move completely from the management of paper-based records to the management of digital records. Although in some instances, public libraries facilities introduced computer-technology solutions, librarians and archivists continue to generate paperbased records that demand more efforts to be properly managed throughout their life cycle. This was also discovered by Ndenje-Sichalwe, Ngulube and Stilwell (2011) in their study on records management that the majority of records in the government ministries in Tanzania have been created and maintained in paper format. Similarly, Asogwa (2012) attests that most offices use computers to assist in some portions of the organisation's recordkeeping and are still producing more paper documents that are stored as records copy.

Stuart and Bromage (2010) observe that large volumes of digital records are created and captured through applications of records management systems and then stored on an organisation's hard drives or networks. However, this process can become expensive as software needed to create the information can be costly (Stuart \& Bromage 2010) and maintenance of the storage option can also create challenges as it needs to be tested constantly for obsolescence, malware and general corruption of data or software. Ngulube and Tafor (2006) also suggest that the management and preservation of digital records are likely to remain a global challenge in the foreseeable future. The problems include technological obsolescence, media longevity, lack of organisational commitment and inadequate resources, limited expertise and the sheer growth of electronic records (Ngulube \& Tafor 2006).

As noted by Li et al. (2015), implementing IoT could be affected by all connected objects and it is thus a challenge to integrate this technology with the current information systems. IoT security protection and privacy may become a limit for its development in public libraries (Weber, 2010). Innovative approaches therefore need to be proposed to ensure security within public libraries, including role-based access control, end-to-end encrypted techniques, publickey encryption, trust management framework and asymmetric public-key cryptography (Sethi et al., 2012). The standardisation also plays a key role for the full deployment of IoT in different organisations; however, the rapid development of IoT makes standardisation difficult (Li et al., 2015). Miorandi et al. (2012) also identifies building privacy-preserving mechanism for IoT applications as a big challenge and therefore innovative solutions need to be identified and further developed.

\section{Human resources capacity in managing the digital records}

The effective management of records depend on staff receiving adequate records management training to enable them to acquire knowledge and skills needed to successfully manage and preserve their digital records. Ngulube (2001) emphasises the need for staff with skills and knowledge as a prerequisite to effective records management. Similarly, in their study, Kemoni and Ngulube (2007) recommended that in order to raise the profile of records management, staff in the registries should be recruited and deployed on the basis of their records management qualifications and experience. Ndenje-Sichalwe (2010) also recommends the provision of a higher level of training in records management among the registry staff through short courses, workshops and seminars. Mthembu and Ocholla (2019) contends that a mixture of disciplinespecific knowledge, skills and personal competencies is required of library and information 
professionals in a digitally oriented environment. Hence, in a digital library environment, the core knowledge and skills of traditional librarianship are also important but need to be augmented by new technological knowledge (Dalkir 2017).

Several studies have also identified key problems with records management, including poor or non-existent training related to the use of digital technologies for the management of digital records, difficulties in retaining qualified staff in the public libraries and a lack of collaboration between records management professionals and other specialists (Mthembu \& Ocholla 2019; Ngulube \& Tafor 2006). Staff retention is another challenge in most of the South African public libraries as trained staff with electronic records management skills regularly leave the public sector for the private sector for better paid positions and these transitions lead to loss of digital records (Erima \& Wamukoya, 2012). Ngoepe, Maluleka and Onyancha (2014) note that archives and records management professionals in Africa are isolated and need increased interdisciplinary collaboration. Ngulube and Tafor (2006) recommend that archival institutions in the ESARBICA region should collaborate with universities that offer archival training in the region in order to get assistance regarding their critical skills needs. The study by Erima and Wamukoya (2012) also recommended that registry staff should collaborate with its ICT department to manage electronic records generated within the institution, using a more egalitarian approach. Collaborations between records management professionals and other specialists are thus crucial in the development of new technologies.

\section{Conclusion and recommendations}

This article reviewed initiatives and previous studies reporting on the application of modern technologies in the management of records in public libraries. Although the libraries made their first step in the management of records in networked environments, some of the libraries have been slowly adopting modern technologies in the management of their records. The problems include lack of understanding of these technologies, poor IT infrastructure, lack IT knowledge and skills and technical support, lack of organisational commitment and inadequate resources. Previous industrial revolutions have also shown us that if industries and institutions do not adapt with modern technologies, they struggle or fail. Public libraries in South Africa thus need to adapt to this fast-changing environment and they need to rethink and reinvent and embrace change. It has been posited that in order to take advantage of the benefits that digital technologies offer in public libraries, archivists, librarians and information professionals need to have the skills and knowledge to do so. In addition, staff should be encouraged to attend records management conferences, workshops and seminars as that will also keep them abreast of emerging trends and technologies in this field. Records management practices need to be understood as a form of accountability, and policies and legislative frameworks for maintaining institutional evidence also need to be developed. The study recommends that public libraries consider exploring the possibility of benchmarking and collaborating with other key sectors for effective implementation of modern technologies and on the extent of their application. Collaboration with other institutions can thus benefit public libraries in deploying innovative systems and engaging in smart information delivery through these technologies. 


\section{References}

Abu-Elkheir M., Hayajneh, M. \& Al, N.A. 2013. Data management for the Internet of Things: Design primitives and solution. Sensors 13(11): 15582-15612.

Amron, M.T., Ibrahima, R., Bakara, N.A. \& Chuprata, S. 2019. Determining factors influencing the acceptance of cloud computing implementation. The fifth Information Systems International Conference. Procedia Computer Science 161:1055-1063. Available at: http://creativecommons.org/licenses/by-nc-nd/4.0/ (Accessed 10 October 2020).

Askhoj, J, Sugimoto, S. \& Nagamor, M. 2011. Preserving records in the cloud. Records Management Journal 21(3): 175-187.

Badimo, K.H. 2017. The Internet of Things - connectivity and interconnectedness. Internet of Things Article.

Bauerle, N. 2017. How does Blockchain technology work? Available at: https://www.coindesk.com/information/how-does-blockchain-technology-work/ (Accessed 15 March 2018).

Beagrie, N. 2006. Digital curation for science, digital libraries and individuals. The International journal of Digital Curation 1(1): 3-16.

Blockgeeks (2016). What is blockchain technology? A step-by-step guide for beginners. Available at: http://blockgeeks.com/guides/what-is-blockchaintechnology/ (Accessed 17 November 2016).

Buckland, M.K. 2017. Library technology in the next twenty years. Library Hi Tech 35(1):112.

Cheng, S., Daub, M., Domeyer, A. \& Lundqvist, M. 2017. Using blockchain to improve data management in the public sector. McKinsey Digital Article. New York.

Christidis, K. \& Devetsikiotis, M. 2016. Blockchains and smart contracts for the Internet of Things, IEEE, 2292-2303.

Corrado, E.M. \& Moulaison, H.L. 2015. Digital preservation and the cloud: Challenges and opportunities. IFLA 2015 Pre-Conference Satellite Meeting Preservation \& Conservation Section. Durban, South Africa, 12-13 August 2015.

Council of Canadians Academies. 2015. Leading in the digital world: Opportunities for Canada's memory institutions. The expert panel on memory institutions in the digital revolution. Ottawa, Canada.

Deloitte. 2016. Bitcoin, blockchain \& distributed ledgers: caught between promise and reality. Centre for the Edge, Melbourne, Victoria: Australia. Available at https://www/audeloitte-technology-bitcoin-blockchain-distributed-ledgers- 180416.pdf (Accessed10 August 2017).

Durst, S. \& Wilhelm, S. 2012. Knowledge management and succession planning in SMEs. Journal of Knowledge Management 16 (4):637-649.

Erima, J.A. \& Wamukoya, J. 2012. Aligning records management and risk management with business processes: a case study of Moi University in Kenya. Journal of the South African Society of Archivists 45: 24-38.

Fleisch, E. 2010. What is the Internet of Things? An economic perspective. Economics, Management, and Financial Markets 5(2): 125-157.

Franks, P.C. 2015. Government use of cloud-based long term digital preservation as a service: an exploratory study. Digital Heritage 2.

Gartner (2016) Blockchain to fundamentally change the society in which we live. Available at: http://www.econotimes.com/Blockchain-to-fundamentally-change-thesociety-inwhich-we live--Gartner419493. (Accessed 10 August 2017). 
Gital, A.Y. \& Zambuk, F.U. 2011. Cloud computing: solution to ICT in higher education in Nigeria. Advances in Applied Science Research 2(6): 364-369.

Ibrahim, A.A. \& Kamalrudin, M. 2018. Security requirements and technologies for the Internet of Things (IOT) applications: a systematic literature review. Journal of Theoretical and Applied Information Technology 96 (17): 5694-5716.

InterPARES.2016. Checklist for cloud service contracts. Available at: https://interparestrust.org/assets/public/dissemination/NA14_20160226_CloudService ProviderContracts_Checklist_Final.pdf. (Accessed 10 July 2019).

Iwhiwhu, B.E. \& Okorodudu, P.O. 2012. Public library information resources, facilities and services: User satisfaction with the Edo State Central Library. Library Philosophy and Practice. Available at: https://digitalcommons.unl.edu/libphilprac/747 (Accessed 10 July 2019).

JISC. 2011. Saving libraries: The battle for time \& resources. Cloud-based library services 32. Available at: http://www.jisc.ac.uk/inform/inform32/SavingLibraries.html (Accessed 10 July 2019).

Kaushik, A. \& Kumar, A. 2013. Application of cloud computing in libraries. International Journal of Information Dissemination and Technology 3(4): 270-273.

Kemoni N.H \& Ngulube P.2007. National archives and the effective management of public sector records in Kenya. Mousaion 25 (2): 120-140.

Lemieux, V, L. 2016. Trusting records: is blockchain technology the answer? Records Management Journal 26(2):110-139.

Liu, W. \& Cai, H.H. 2013. Embracing the shift to cloud computing: knowledge and skills for systems librarians. OCLC Systems \& Services: International Digital Library Perspectives 9(1): 22-29.

Liu, X.L. 2015. Analysis and management platform construction of library's big data based on Internet of Things. In Lee, G. (Ed.) Advances in education research. Information Engineering Research Institute 84:157-163.

Maseh, E. 2016. E-government implications for records management in Africa: a review of literature. Journal of the South African Society of Archivists 49: 89-101.

Massis, B.E. 2016. The Internet of Things and its impact on the library. New Library World 117(3/4): 289-292.

Mell, P. \& Grance, T. 2011. The NIST definition of cloud computing (draft): Recommendations of the National Institute of Standards and Technology. NIST Special Publication 800:7.

Miorandi, D., Sicari, S., De Pellegrini, F. \& Chlamtac, I. 2012. Internet of Things: vision, applications and research challenges. Ad Hoc Networks 10(7): 1497-1516.

Modiba, T.M., Ngoepe, M. \& Ngulube, P. 2019. Application of disruptive technologies to the management and preservation of records. Mousaion: South African Journal of Information Studies 37(1).

Mthembu, M.S \& Ocholla, D. 2019. Perceptions on Job Requirements of LIS Graduates in Public Libraries: A Reflection on Public Libraries in KwaZulu-Natal, South Africa Mousaion 36(4):1-25.

National Institute of Standards and Technology (NIST). 2011. Guidelines on security and privacy in public cloud computing. Available at: http://www.nist.gov/manuscriptpublication-search.cfm?pub_id=909494 (Accessed 10 December 2018).

Ndenje-Sichalwe, E.N. 2010. The significance of records management to fostering accountability in the public service reform programme of Tanzania. $\mathrm{PhD}$ Thesis, University of KwaZulu-Natal, Pietermaritzburg. 
Ndenje-Sichalwe, E, Ngulube, P. \& Stilwell, C. 2011. Managing records as a strategic resource in the government ministries of Tanzania. Information Development 27(4):264-279.

Niederberger, M. 1999. Library audit shows uncontrolled system. Pittsburgh: Pittsburgh PostGazette.

Ngoepe, M., Maluleka, J. \& Onyancha, O.B. 2014. Research collaboration in the archives and records management field across and beyond universities in Africa: an informetric analysis. Mousaion 32 (3): 119-35.

Ngoepe, M. \& Saurombe, A. 2016. Provisions for managing and preserving records created in networked environments in the archival legislative frameworks of selected member states of the Southern African development community. Archives and Manuscripts 44(1): 24-41.

Ngulube, P. \& Tafor, V.F. 2006. The management of public records and archives in the member countries of ESARBICA. Journal of the Society of Archivists 27 (1): 57-83.

Ngulube, P. 2001. Guidelines and standards for records management education and training: a model for Anglophone Africa. Records Management Journal, 11 (3):155-173.

Oyelude, A.A. 2016. What's trending in libraries from the internet cyber sphere-bookless libraries? Library Hi Tech News 33(6):19-20.

Nwosu, M.C. 2017. The future of the 21st century libraries is hybrid. Computing \& Information Systems 21(1).

Patel, Y. 2011. Cloud computing and its impact on library services. INFLIBNET Newsletter 18(1): 17-20.

Pujar, S.M. \& Satyanarayana, K.V. 2015. Internet of Things and libraries. Annals of Library and Information Studies 62:186-190.

Raju, J. 2014. Knowledge and skills for the digital era academic library. The Journal of Academic Librarianship 40:163-170.

Rein, L. \& Peterson, A. 2015. What you need to know about the hack of government background investigations. The Washington Post. Washington.

Renold, A.P. \& Rani, R.J. 2013. An internet based RFID library management system. Proceedings of 2013 IEEE Conference on Information and Communication Technologies. IEEE, New York. 932-936.

Ross, S. 2007. Digital Preservation, Archival Science and Methodological Foundations for Digital Libraries, Keynote Address at the $11^{\text {th }}$ European Conference on Digital Libraries (ECDL). Budapest: HATII at the University of Glasgow.

Salesforce. 2015. What is cloud computing? Salesforce platform. San Francisco: California

Scale, M.E.2010. Assessing the impact of cloud computing and web collaboration on the work of distance library services. Journal of Library Administration 50(7/8): 933-950.

Sethi, M, Arkko, J. \& Keränen, A. 2012. End-to-end security for sleepy smart object networks, Proceedings of the 37th Conference on Local Computer Networks Workshops, IEEE, Clearwater, New York, 973-981.

Shaw. 2016. Smart surveillance: an enterprise-grade video surveillance solution for small and medium-sized businesses. United State of America: California. Available at: http://business.shaw/internet/smartsurveillance (Accessed 18 July 2020).

Straw, J. 2017. IDisrupted - an introduction to Blockchain technology. Available at: https://disruptionhub.com/idisrupted-an-introduction-toblockchaintechnology (Accessed 17 May 2017).

Srivastava, J.P. \& Verma, V.K. 2015. Cloud computing in libraries: Its needs, applications, issues and best practices. Emerging Trends and Technologies in Libraries and Information Services (ETTLIS), 2015 4th International Symposium on Noida 33- 38. 
Stuart, K. \& Bromage, D. 2010. Current state of play: Records management and the cloud. Records Management Journal 20 (2): 217-25.

Sudhier, K.G. \& Seena, S.T. 2018. Library professionals' adoption of cloud computing technologies: A case study on Kerala University Library, India. Library Philosophy and Practice 5-14.

Swain, D.K. 2014. Cloud computing and its application in library management: A review of research. e-Library Science Research Journal 2(4): 1-9.

Tapscott, D. \& Tapscott, A. 2016. The Tapscotts on Blockchain in 2016 and what's next? Available at: http://www.coindesk.com/the-tapscotts-on-blockchain-2016-and-whatsnext/ (Accessed 10 January 2017).

Trautman, L.J.2016. Is Disruptive Blockchain Technology the Future of Financial Services? The Consumer Finance Law Quarterly Report 69: 232. (Accessed 31 May 2016).

Umeh, J. 2016. Blockchain double bubble or double trouble? ITNOW 58(1):58-61.

Wada, I. 2018. Cloud computing implementation in libraries: A synergy for library services optimization. International Journal of Library and Information Science 10(2):17-27.

Weber, R.H. Internet of Things: new security and privacy challenges. Computer Law \& Security Review 26 (1): 23-30.

White Paper Blockchain in Trade Facilitation Version 2. 2019. UNECE: UN/CEFACT.

Wojick, M. 2016. Internet of Things - potential for libraries. Library Hi Tech 34(2): 404-420.

Yakel, E. \& Colligan, C.A. 2001. Public library records: Issues of accountability and access. Public Library Quarterly 19(4): 5-20.

Yang, H. \& Tate, M. 2012. A descriptive literature review and classification of cloud computing research. Communications of the Association for Information Systems 31: $35-60$.

Yuvaraj, M. 2015. Inherent conceptions of cloud computing among library and information science professionals. Library Philosophy and Practice. Available at http://digitalcommons.unl.edu/libphilprac/1321 (Available 10 July 2019). 